\title{
Reattachment of fractured teeth fragments in mandibular incisors: a case report
}

This article was published in the following Dove Press journal:

International Medical Case Reports Journal

6 April 2015

Number of times this article has been viewed

\section{Mohammed K Yousef}

Department of Operative Dentistry, Faculty of Dentistry, King Abdulaziz University, Jeddah, Saudi Arabia
Correspondence: Mohammed K Yousef Department of Operative Dentistry, Faculty of Dentistry, King Abdulaziz University, PO Box 80209, Jeddah, 21589, Saudi Arabia

$\mathrm{Tel} / \mathrm{fax}+966$ I2 6403443 ext 21012

Email myousf@kau.edu.sa

\begin{abstract}
The majority of dental trauma involves anterior teeth, especially the maxillary central incisors. A mandibular incisor fracture with or without pulp tissue involvement is considerably less common. Different approaches for treating these fractured teeth have been reported in the literature. The type of treatment rendered depends mainly on the extent of fracture, pulp involvement, radicular fracture, biologic width infringement or violation, and presence of the fractured piece. This case report illustrates reattachment of fractured fragments on two mandibular incisors without pulp exposure using a new proposed reattachment method using a combination of two different types of composite materials together with an orthodontic lingual retention wire. An 8-year-old female patient presented with fractured mandibular left incisors (Ellis class II fracture). Broken pieces were saved and brought in a closed container in water. Periapical radiographs revealed no evidence of pulpal involvement in either tooth and no periapical radiolucency was noticed. Fractured fragments and the broken teeth were prepared with circumferential bevels. Reattachment of the fractured fragments were done using two types of composite resin materials and a lingual orthodontic retention wire was also used. The patient was recalled after 8 months to follow up both teeth. Clinical examination revealed excellent composite restorations covering the fracture lines.
\end{abstract}

Keywords: reattachment, fractured teeth, dental trauma

\section{Introduction}

Oral trauma is a frequent injury and can be as high as $18 \%$ in a young population. ${ }^{1-3}$ Of these traumas, clinical crown fractures are the most frequent in anterior teeth with an incidence that ranges between $2 \%$ and $5 \% .{ }^{4-6}$ Children nowadays get involved in dangerous sports activities which would lead to an increase in dental trauma incidence. ${ }^{7}$ Different approaches for treating these fractured teeth have been reported in the literature. The type of treatment rendered depends mainly on the extent of fracture, pulp involvement, radicular fracture, biologic width infringement or violation, and presence of the fractured piece. ${ }^{8}$ Several authors have classified dental trauma based on the aforementioned factors. ${ }^{1,9-11}$ Reattaching fractured pieces is a preferred technique among clinicians because of its advantages of saving time and better esthetic end result. Several methods to reattach these fractured fragments are described in the literature. ${ }^{12-16}$ This case report illustrates reattachment of fractured fragments on two mandibular incisors (Ellis class II fracture) without pulp exposure using a new proposed reattachment method using a combination of two different types of composite restorations together with an orthodontic lingual retention wire. 


\section{Case report}

An 8-year-old female patient came to the clinic with her parent having fractured her mandibular left incisors (teeth number 31 and 32) the previous day (Figure 1). The fractured fragments of both teeth were kept in a small container and immersed in tap water. The patient was playing with a toy when it slipped and hit and fractured her teeth. Clinical examination revealed that both teeth had an Ellis fracture class II, which meant that there was an extended crown fracture with dentin involvement but without pulp exposure (Figure 1). There were oblique fractures extending mesiodistally and involving the incisal and middle third of tooth number 31 while the fracture of tooth number 32 also involved the cervical third. Both teeth were already covered with glass ionomer cement temporary fillings which were placed within 2 hours after the trauma by a general dentist who advised them to keep the fractured fragments and present them to a specialist to reattach them (Figure 2). Gingival and periodontal tissues surrounding both teeth were healthy and unremarkable. The patient was not experiencing any pain related to either tooth. Vitality test using cold test revealed normal response while percussion tests were normal and unremarkable.

\section{Radiographic presentation}

Periapical radiographs were taken for both teeth. There was no evidence of pulpal involvement in either tooth and no periapical radiolucency noticed.

\section{Fractured fragment cleaning and try-in}

Both fractured fragments were cleaned with prophylactic paste and kept aside (Figure 3). After removal of the temporary fillings on both teeth using a low-speed round-head bur, the fractured fragments were tried on to check if there were any missing pieces from either tooth

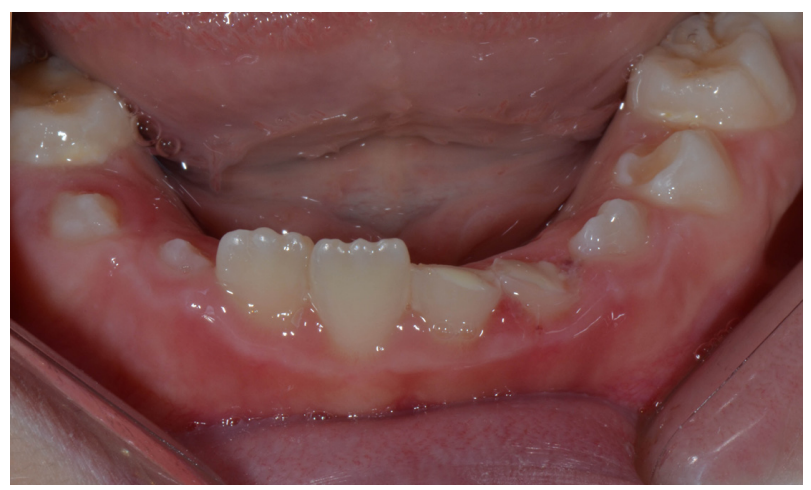

Figure I Frontal view of fractured mandibular teeth.

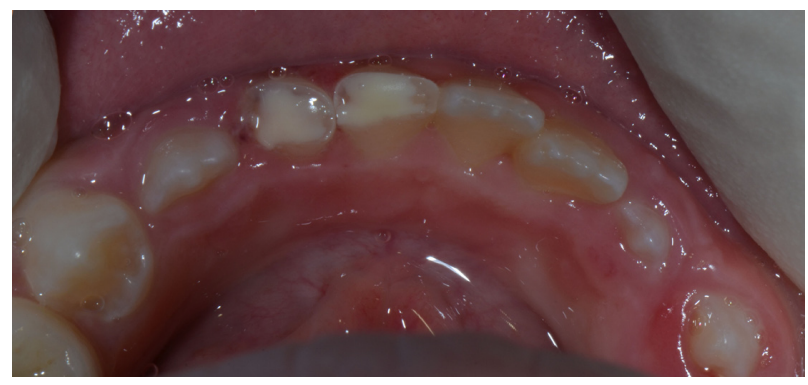

Figure 2 Occlusal view of fractured teeth. Glass lonomer Cement is covering the fractured teeth.

and to determine which piece belonged to which tooth. Both fragments fit perfectly and there were no chipping or missing small fractured pieces. Each fractured fragment was identified and coupled to its fractured counterpart. Shade was determined to be $\mathrm{A} 2$ using classic Vita shade guide.

\section{Tooth preparation}

Both fractured teeth received a circumferential bevel which encompassed the whole fractured tooth and it was $1.5 \mathrm{~mm}$ wide and $0.5 \mathrm{~mm}$ in depth (Figure 4). The width of the bevel was limited to $1.5 \mathrm{~mm}$ to keep the bevel away from the gingiva by $1 \mathrm{~mm}$. A straight diamond bur was used to this effect.

\section{Fractured fragment preparation}

Both fragments also received a similar circumferential bevel which encompassed the whole fractured piece and it was $3 \mathrm{~mm}$ in width and 0.5 in depth (Figure 5). Both fragments were then acid-etched for 20 seconds on the exterior surfaces (labial, lingual, mesial, and distal) and 15 seconds on the interior surfaces where dentin was involved using $35 \%$ phosphoric acid. Both were then rinsed thoroughly and then dried for 5 seconds each, and then kept separate.

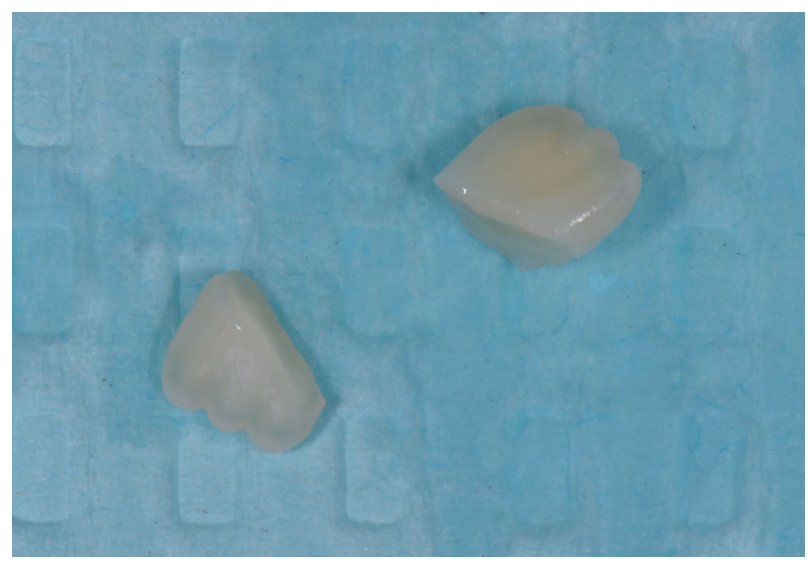

Figure 3 Fractured fragments after cleaning 


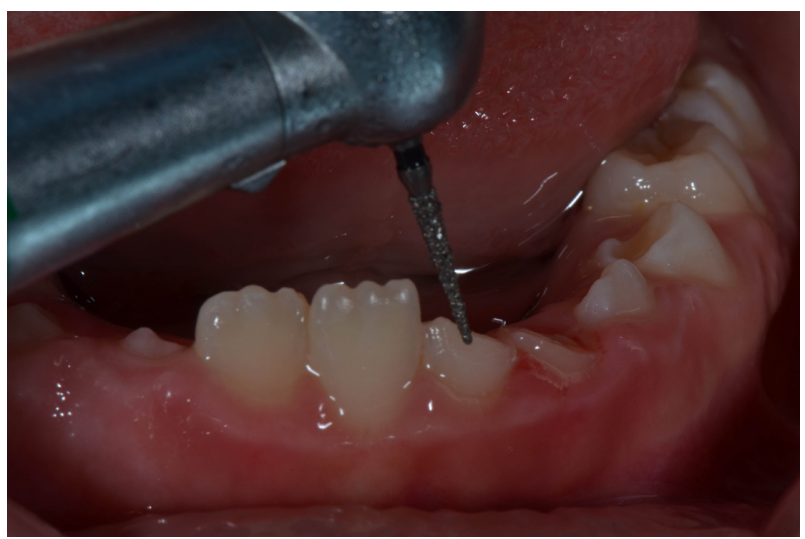

Figure 4 Circumferential enamel bevel placed on both fractured teeth.

\section{Bonding procedure}

After isolating the field, both fractured teeth were acid-etched for 20 seconds on the exterior enamel surfaces and 15 seconds on the interior dentin surfaces using $35 \%$ phosphoric acid. Both teeth were rinsed thoroughly for 10 seconds and then dried for 5 seconds, keeping dentin moist and enamel dry. Adhesive layers were then placed using Single Bond Universal Adhesive (3M/ESPE, St Paul, MN, USA) according to manufacturer's instructions, after which it was light cured with an LED curing light for 10 seconds (Elipar ${ }^{\mathrm{TM}}$; 3M/ESPE).

Enamel shade of A2 Filtek Z350 XT Flowable Restorative (3M/ESPE) composite was used. It was placed on top of one fractured tooth, and then the fractured fragment was pressed in place. Excess flowable composite was removed with an applicator tip and the cementation was finalized with light curing for 20 seconds labially and lingually. The same procedure was done for the other tooth. After cementing both pieces with the flowable composite, enamel shade of A2 Filtek Z350 XT Universal Restorative was placed labially and lingually to cover the fractured lines

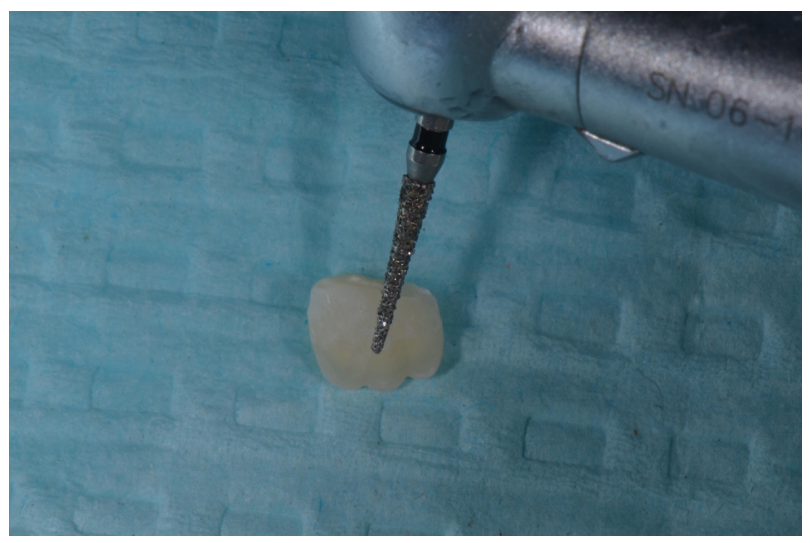

Figure 5 Fractured fragments received a circumferential enamel bevel.

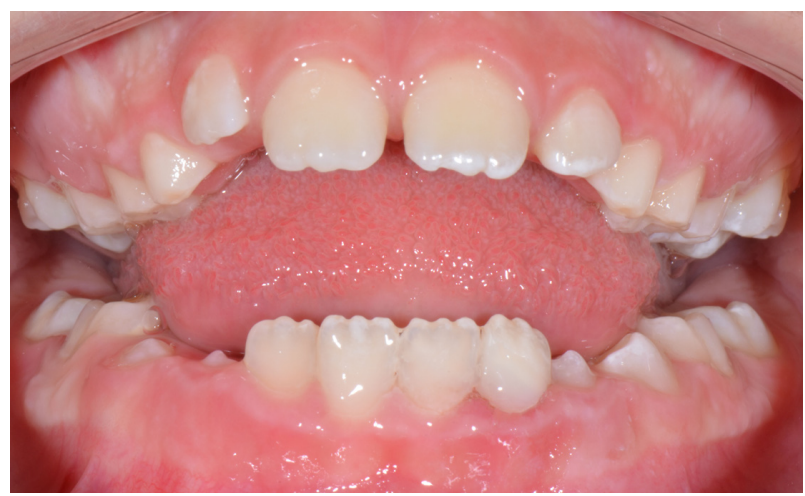

Figure 6 Frontal view showing excellent esthetics of attached fragments.

and the bevels surrounding them. After light curing both, the placed composite was finished and polished using an Astropol ${ }^{\circledR}$ finishing and polishing kit (Ivoclar Vivadent, Schaan, Liechtenstein) (Figure 6). Finally, a solid gold chain retainer (Ortho FlexTech Dental Retention System; Reliance Orthodontic Products, Inc., Itasca, IL, USA) was bonded to the lingual aspect of teeth number 32,31, and 41 for extra means of retention.

\section{Recall}

The patient was recalled after 8 months to follow up both teeth. Clinical examination revealed excellent composite restorations covering the fracture lines (Figure 7). Some plaque accumulation was noticed against the palatal surfaces of bonded teeth with mild gingival inflammation (Figure 8). Both teeth responded normally to cold test and there were negative percussion responses. Radiographic examination of periapical X-rays revealed normal and unremarkable bone tissue surrounding both teeth (Figure 9).

\section{Discussion}

Several methods of attaching fractured fragments to teeth are described in the literature. ${ }^{8,12-16}$ In this case, a circumferential

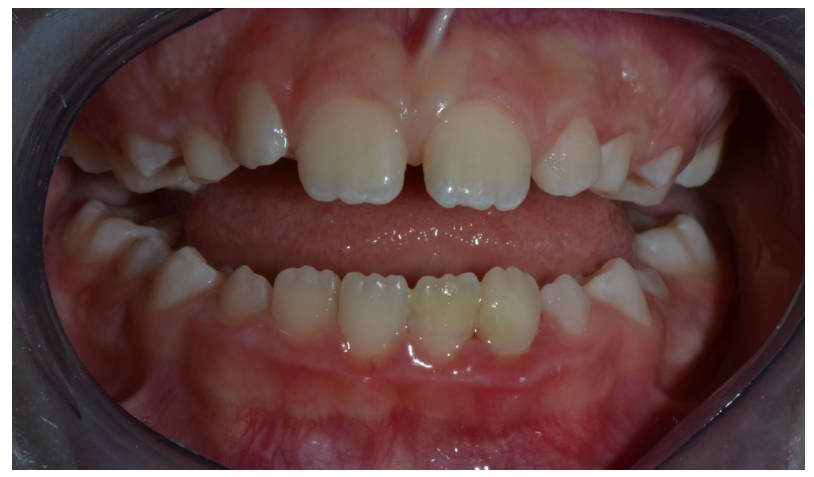

Figure 7 Frontal view of teeth after 8 month recall. 


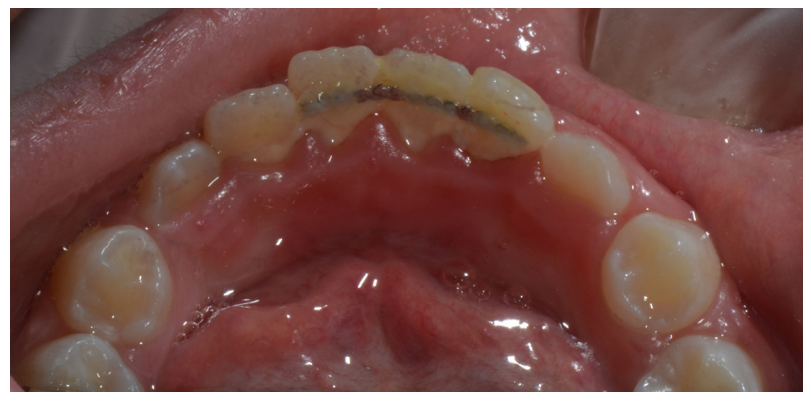

Figure 8 Lingual view showing the retainer in place. Some plaque accumulation noticed.

bevel was prepared on the fractured teeth of which the width was limited to $1 \mathrm{~mm}$ to stay away from the gingival margin. The use of a bevel labially and lingually has been shown to significantly increase the shear bond strength of the reattached fragment. ${ }^{17}$ On the other hand, the fractured fragments received a wider bevel of $3 \mathrm{~mm}$ which was also circumferential and ended with feather chamfer line. The chamfer line also was reported to provide better strength recovery as compared to non-chamfered reattached fragment. ${ }^{18}$

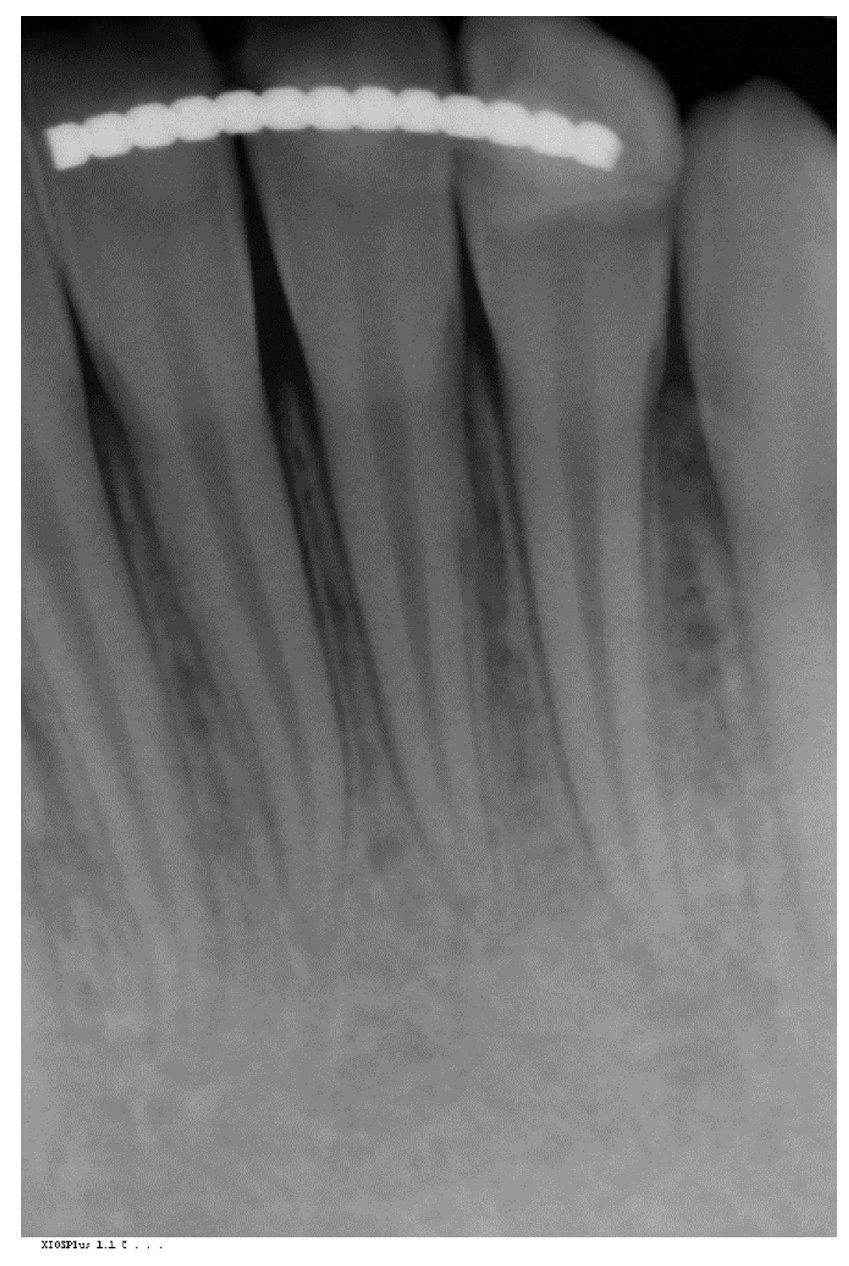

Figure 9 Periapical radiograph of mandibular incisors showing healthy pulp and periodontal tissues.
Although one study has reported that building fractured teeth in vitro with composite restoration provided better fracture strength recovery over reattached fragments, ${ }^{18}$ one cannot ignore the obvious advantages of reattaching fractured fragments. Esthetic parameters of color, translucency, opalescence, contour, and texture are all preserved. Wear, abrasion, and staining will also be reduced or avoided. The fact that reattaching these fragments would save time and costs cannot be overlooked. Instead of building up a composite filling to restore the missing fractured fragments, one would bevel the fractured remaining tooth structure along with the fractured segments and then bond them to the existing tooth. This cuts the clinical time and obviously reduces the cost of the procedure as it will be a modified cementation procedure instead of a whole session of building up the tooth with composite restoration and then finishing/polishing it to proper esthetic and function which will not be needed in cases of reattachment. However, this technique would not be a treatment option if these pieces were lost and the patient was not aware of how important it is to bring in these fractured fragments. Patients should be educated about dental traumas and how best to store fractured fragments to increase the chance of success in reattaching them. ${ }^{19}$

Similar studies in the literature report using one type of composite restoration or adhesive bonding agent to cement fractured segments. In this case, however, two different types of composite restorative were used. The flowable type was used to attach the two pieces together since it is of low viscosity and should flow and fill in the gap between fractured pieces and at the same time does not produce porosities or voids like resins of higher viscosity. The nanocomposite chosen to cover the beveled and chamfered areas labially and lingually was used for its better esthetic, physical, and mechanical properties.

Reattaching fragments can be used to restore fractured teeth, presumably with sufficient strength; however, longterm follow-up is necessary to monitor the durability of the reattached fragments and regularly assess the vitality of the teeth.

Lingual fixed retention wire was used in this case to add more retention to the reattached fragments. Another reason was that the patient has a deep bite, and that may compromise the longevity of the reattached fragments. Such wires are used to fix mobile teeth together or to splint avulsed teeth, ${ }^{7-14}$ but in this case it was used to offer more retention of the fractured pieces. So, the combination of different materials used together with the lingual retention wire is what makes this case management unique. Laboratory and clinical studies 
are warranted to recommend using these retention wires as a standard of care for such cases. The decision to use wires has to take into consideration the eruption stage of teeth and whether such wires would interfere with or hinder eruption of retained teeth. In this case, teeth were fully erupted and a consult with an orthodontist was obtained beforehand. It is crucial to monitor oral hygiene closely so that calculus and plaque do not accumulate in that area. The presence of plaque and gingival inflammation around these teeth was brought to the attention of both the patient and the parent. The patient was reluctant to clean this area in fear of breaking the teeth again. She was encouraged to brush regularly. Supervised tooth brushing by the parent was also suggested and encouraged.

\section{Conclusion}

Reattachment of fractured fragments of teeth should always be considered as a first option when conditions permit. Such an option saves time and cost on the patient since it is considered a modified cementation procedure instead of a composite restoration build-up, while at the same time preserves the natural anatomy, contour, texture, color, and the physical properties of natural dentition. Closely following such cases, monitoring their oral hygiene, and documenting them are very important for establishing consensus regarding best clinical protocols, guidelines, and approaches for such cases.

\section{Disclosure}

The author reports no conflicts of interest in this work.

\section{References}

1. Andreasen JO, Andreasen FM, Andersson L. Textbook and Color Atlas of Traumatic Injuries to the Teeth. 4th ed. Oxford: Blackwell Munksgaard; 2007.

2. Petersson EE, Andersson L, Sörensen S. Traumatic oral vs non-oral injuries. Swed Dent J. 1997;21:55-68.
3. Glendor U, Halling A, Andersson L, Eilert-Petersson E. Incidence of traumatic tooth injuries in children and adolescents in the county of Västmanland, Sweden. Swed Dent J. 1996;20:15-28.

4. Stockwell AJ. Incidence of dental trauma in the Western Australian School Dental service. Community Dent Oral Epidemiol. 1988;16: 294-298.

5. Hamilton FA, Hill FJ, Holloway PJ. An investigation of dento-alveolar trauma and its treatment in an adolescent population. Part I: the prevalence and incidence of injuries and the extent and adequacy of treatment received. Br Dent J. 1997;182:91-95.

6. Oluwole TO, Leverett DH. Clinical and epidemiological survey of adolescents with crown fractures of permanent anterior teeth. Pediatr Dent. 1986;8(3):221-225.

7. Zerman N, Cavallieri G. Traumatic injuries to permanent incisors. Endod Dent Traumatol. 1993;9:61-64.

8. Reis A, Loguercio AD, Kraul A, Matson E. Reattachment of fractured teeth: a review of literature regarding techniques and materials. Oper Dent. 2004;29:226-233.

9. Ellis RG, Davey KW. The Classification and Treatment of Injuries to the Teeth of Children. Chicago: Year Book Medical; 1970:13-16.

10. Spinas E, Altana M. A new classification for crown fractures of teeth. J Clin Pediatr Dent. 2002;26:225-231.

11. Baratieri LN, Monteiro S Jr, Andrada MAC. Esthetics: Direct Adhesive Restorations on Fractured Anterior Teeth. Chicago: Quintessence Books; 135-205.

12. Burke FJ. Reattachment of a fractured central incisor tooth fragment. Br Dent J. 1991;170:223-225.

13. Diangelis AJ, Jungbluth M. Reattaching fractured tooth segments: an esthetic alternative. J Am Dent Assoc. 1992;123:58-63.

14. Reis A, Francci C, Loguercio AD, Carrilho MR, Rodrigues Filho LE Re-attachment of anterior fractured teeth: fracture strength using different techniques. Oper Dent. 2001;26:287-294.

15. Simonsen RJ. Restoration of a fractured central incisor using original tooth fragment. J Am Dent Assoc. 1982;105:646-648.

16. van der Vyver PJ, Marais JT. Reattachment of a fractured tooth fragment: a case report. J Dent Assoc S Afr. 1996;51:623-624.

17. Chazine M, Sedda M, Ounsi H, Paragliola R, Ferrari M, Grandini S. Evaluation of the fracture resistance of reattached incisal fragments using different materials and techniques. Dent Traumatol. 2011;27: $15-18$.

18. Reis A, Kraul A, Francci C, et al. Re-attachment of anterior fractured teeth: fracture strength using different materials. Oper Dent. 2002;27:621-627.

19. Ferraz J, Pécora JD, Saquy PC, Sousa-Neto MD. Treatment of oblique crown fractures in maxillary premolars using adhesive tooth fragment reattachment: 19 years of follow up. Dent Traumatol. 2001;27: $455-459$.
International Medical Case Reports Journal

\section{Publish your work in this journal}

The International Medical Case Reports Journal is an international, peer-reviewed open-access journal publishing original case reports from all medical specialties. Previously unpublished medical posters are also accepted relating to any area of clinical or preclinical science. Submissions should not normally exceed 2,000 words or

\section{Dovepress}

4 published pages including figures, diagrams and references. The manuscript management system is completely online and includes a very quick and fair peer-review system, which is all easy to use. Visit $\mathrm{http} / / / \mathrm{www}$.dovepress.com/testimonials.php to read real quotes from published authors. 